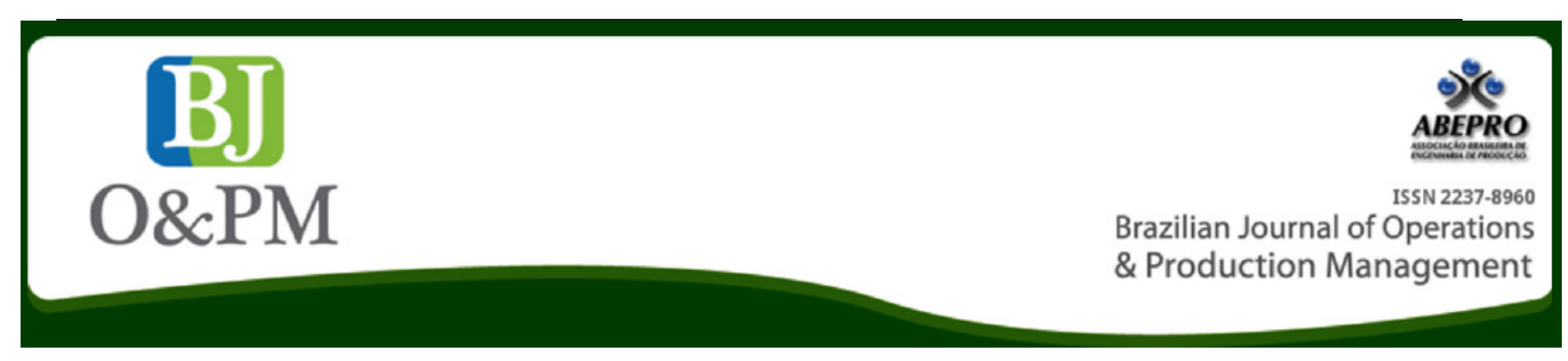

\title{
MOTIVES AND BENEFITS OF ISO 9001 QUALITY MANAGEMENT SYSTEM: AN EMPIRICAL STUDY OF INDIAN SMES
}

\author{
Asif Khan'; Jamal Ahmad Farooquie ${ }^{a}$ \\ a Aligarh Muslim University (AMU) - Aligarh, UP, India
}

\begin{abstract}
The present study aims to investigate the motives and benefits of certification to ISO 9001 among Indian SMEs of manufacturing and service sectors. The main objective of this paper is to provide empirical evidence on SMEs' motivation to pursue ISO 9001 quality management system (QMS) and the benefits they receive from being certified to ISO 9001 . First, several studies about the benefits and motivations of QMS in various countries are reviewed, and then a questionnaire is sent to 800 ISO 9001 certified SMEs, representing both manufacturing and service sectors in India. Only 115 valid responses are processed and analysed. The survey findings indicate that majority of the SMEs meet the purpose and spirit of ISO 9001 for which it was designed and developed to bring the quality practices and culture into the organization and improve the operational and financial results of the organisations. However, the motives and benefits of certification have reported very weak association across SMEs of manufacturing and service sectors. In addition, ISO 9001 certification, widely regarded as a tool that improves the profits and motivates organisations to pursue it has found significant difference across manufacturing and service sectors SMEs.
\end{abstract}

Keywords: ISO 9001, Quality management System (QMS), Benefits of ISO 9001, SMEs. 


\section{INTRODUCTION}

Over the last 15 years, there has been a rapid growth of ISO 9001 certificates in the developing countries in general and India in particular. The ever growing number of ISO 9001certificates makes India one of the top ten countries in the world. With 41,016 ISO 9001 certificates, according to ISO Survey 2014, India ranks fifth in terms of the number of certified organisations among 188 countries (Table1). However, the worldwide growth of ISO 9001 has slowed down and reported minimal $1 \%$ growth over the previous year as compared to other standards of ISO family giving an indication of its saturation level (Figure 1). In contrast, the number of ISO 9001certified organisations across Asia where developing countries are in the majority is continuously increasing (Figure 2). This growing number of ISO 9001certified organisations in developing countries has raised concerns among the quality practitioners and policy makers about the quality and credibility of the certification. As Conti (2004) unless some substantial changes are made.
In fact, the higher TQM content of the new standards makes the task even harder. If nothing changes, certification reliability will decrease and so will trust. The risk exists for quality certification to become more a kind of bureaucratic requirement by public administrations than a widespread request in $\mathrm{B} 2 \mathrm{~B}$ relations. On the other hand, awards too have lost their allure and, to improve participation, intermediate recognition levels have been conceived ('Levels of Excellence', according to EFQM, points out the concern very precisely in one of his articles; "Had ISO 9000 certification been a decisive factor in quality improvement, we would see a general, widespread increase in product and service quality around the world".

In recent years, however, many researchers started questioning whether accredited certification to ISO 9001 has been achieving the desired results, or whether it has been turned into a documented system which is a mere cosmetic treatment of existing procedures/practices (Acharya et Ray 2000).

$$
1
$$

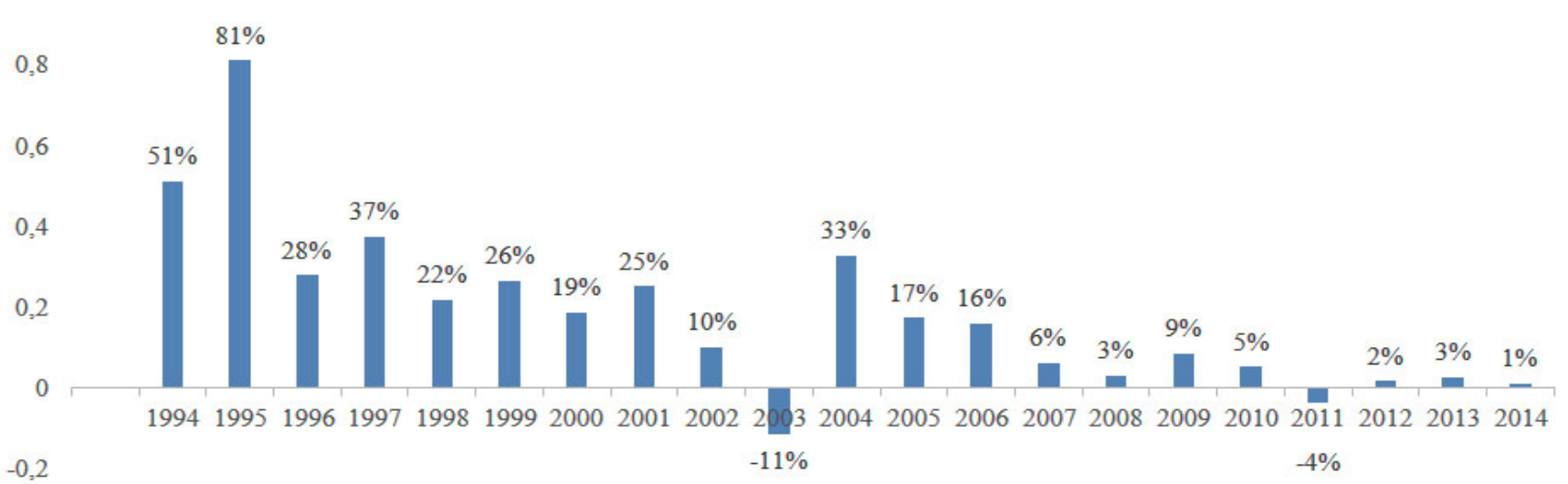

Figure 1. ISO 9001 annual growth worldwide Source: ISO survey 2014

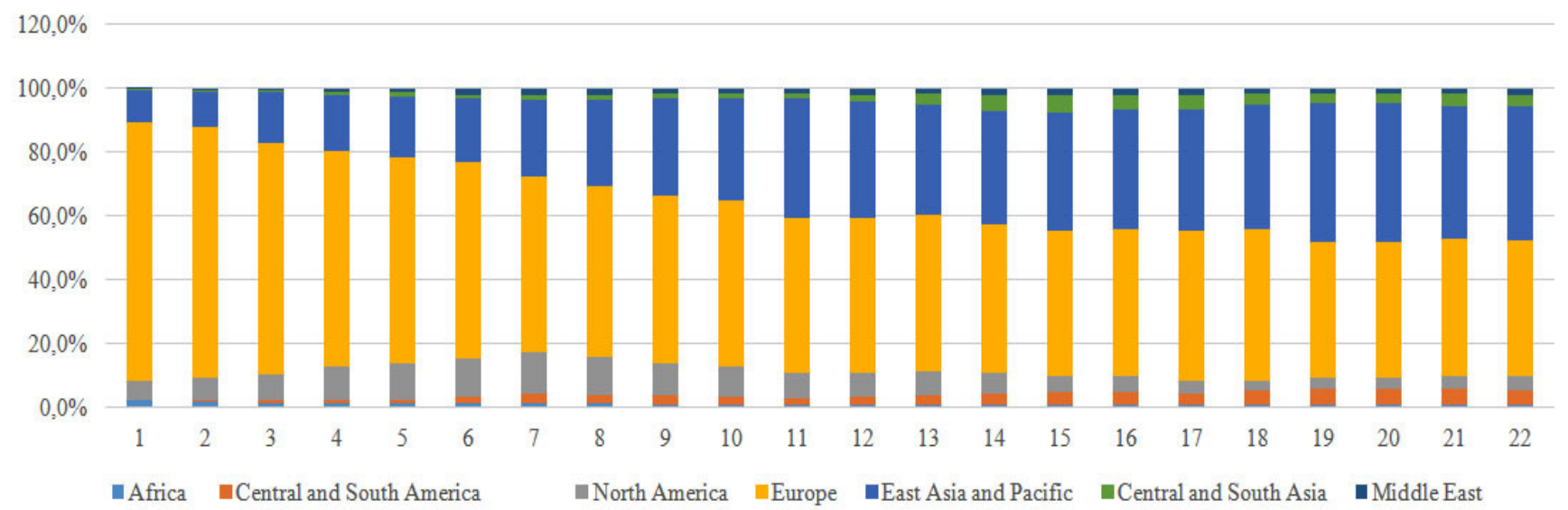

Figure 2. Regional share of ISO 9001 Source: ISO survey 2014 
Table 1. Top 10 countries for ISO 9001 certificates

\begin{tabular}{|c|c|c|}
\hline 1 & China & 342800 \\
\hline 2 & Italy & 168960 \\
\hline 3 & Germany & 55363 \\
\hline 4 & Japan & 45785 \\
\hline 5 & India & 41016 \\
\hline 6 & United Kingdom & 40200 \\
\hline 7 & Spain & 36005 \\
\hline 8 & USA & 33008 \\
\hline 9 & France & 29122 \\
\hline 10 & Australia & 19731 \\
\hline
\end{tabular}

Despite substantial literature on the ISO 9001 standards, there is still much debate concerning the standards' real benefits, motivation to pursue, effectiveness, and its impact on the organizational performance. The extent to which organisational performance can effectively be improved through ISO 9001 certification remains an important issue. Since certification is only a guarantee that the company is using a quality management system according to a list of requisites and procedures. However, the benefits that have been attributed to ISO 9001 have often been overstated, so that organisations tend to generate high expectations that are difficult to realize completely (Alfonso Rodríguez-Escobar et al., 2006)the benefits that have been attributed to ISO 9000 have often been overstated, so that companies tend to generate high expectations that are difficult to realize completely. Many small and medium size organisations (SMEs) have increasingly started questioning the link between ISO 9001 and its real benefits because of their scarce resources that make certification to ISO 9001 a costly affair to afford and implement it.

India's SME sector is one of the primary drivers of its economy. Approximately 34 million SMEs contribute around $45 \%$ of total manufacturing output, $40 \%$ of total export and employ around $40 \%$ of its workforce (MSME, 2014). Despite this large numbers of SMEs and continuously growing number of ISO 9001 certified organisations, the Indian SMEs suffer from quality related issues and do not stand in competition with their counterparts in industrialised countries. This puts the quality of ISO 9001 certification in Indian SMEs in question to probe the real motives of adopting it and if adopted then what benefits they receive from implementing it. This research investigates the motives behind certification to ISO 9001 and tries to identify the benefits from implementing it in Indian SMEs.

In addition, in spite of the increasing amount of research on ISO 9001 quality management system (QMS), most of it is not empirical based on SMEs covering both manufacturing and service sectors. In general, studies investigating the benefits and motives of ISO 9001 have shown mixed results. Some studies have shown external motivation such as 'pressures from customers, markets' to pursue ISO 9001 as the main reasons; while others have shown internal motivation such as 'commitment to quality improvement and improvement of internal processes' as the main reasons. However, based on a comprehensive review of the relevant literature on the benefit of ISO 9001, Rusjan and Alic, have concluded that there are contradictory findings between ISO 9001 and performance indicators of the organisations (Rusjan \& Alic, 2010). Moreover, given those previous research on the benefits of ISO 9001, many of them are focused only on either manufacturing sector or services sector and not on both. Those are also only based on the large organisations rather than those of small and medium size organizations (SMEs). Consequently, there is an opportunity gap to investigate the real benefits and motives of the ISO 9001 in the context of SMEs in a developing country like India. This paper presents empirical evidence on the debated effects of ISO 9001 on organisations in the Indian context and is useful especially for SMEs and governments agencies to learn whether ISO 9001 does or does not meet its purposes and objectives.

Rest of the paper is structured in five sections. An overview of ISO 9001 objectives and a literature review on its motives and benefits are developed in the next section followed by research methodology and analysis of the data. The next sections present results and discussion. The last two sections present conclusion, limitations and implications for future research.

\section{LITERATURE REVIEW}

\subsection{ISO 9001 objectives}

ISO 9001 certification stands for certain minimum quality standards that organisations should meet, and is said to assure a consistent quality of products, services and processes (Singels etal. 2001). It is based on two key concepts: a clear understanding of the organisational processes and their interactions to ensure product conformity; and the management of those processes and the system as a whole, using a "Plan-Do-Check-Act" methodology. It is applicable to any kind of organisation; large or small, private or public, and in the manufacturing, service or other economic sectors. As a result, ISO 9001 has been widely accepted around the world as a basis for organisations to provide confidence in their ability to understand customer and statutory/regulatory requirements, and to systematically provide products and services that meet those requirements. The value of certification is the degree of public confidence and trust that is established by an impartial and competent assessment by a third-party auditor. The organisations's current and potential customers can be confident that their supplier 
has indeed defined its processes and is managing them in a way that will consistently provide them with conforming products/services.

The standard that is used as a basis for certification, at present is ISO 9001:2008 "quality management systems'requirements", for which the stated objectives, according to Clause 1.1 of ISO are:

"To specify requirements for a quality management system where an organization

a) Needs to demonstrate its ability to consistently provide product that meets customer and applicable statutory and regulatory requirements, and

b) Aims to enhance customer satisfaction through the effective application of the system, including processes for continual improvement of the system and the assurance of conformity to customer and applicable statutory and regulatory requirements"

\subsection{Motives and benefits of ISO 9001}

Motivation to pursue certification influence the performance of the standard and vary according to firm size. Small, medium and large firms have varied interests and motives and thus, have different effects of certification on their performance (Arauz et Suzuki 2004). According to ISO (International Organisation for Standardisation), ten stated benefits/motives can be derived by the certified SMEs which tend to motivate organizations to pursue ISO 9001 certification (ISO, 2014).

i. ISO standards help improve the quality of goods and services

ii. ISO standards help drive growth, cut costs and increase profits

iii. ISO standards give business a competitive edge

iv. ISO standards open up export markets for goods and services

v. ISO standards open doors to new customers and strengthen existing business

vi. ISO standards help compete with bigger enterprises

vii. ISO standards enhance credibility and secure customer confidence

viii. ISO standards sharpen business processes and increase efficiency

ix. ISO standards strengthen marketing pitch

x. ISO standards help comply with regulations

However, the benefits for SMEs being certified to ISO 9001 reported by ISO are criticized by few studies. The critics point out the extra burden ISO 9001 puts on SMEs such as; extra costs for achieving ISO certification, an increase in paper workload, no attention for development of personnel, and little attention for the support functions in an organization. In addition, ISO 9001 certification may discourage creative and critical thinking in an organisation because employees are forced to work. Moreover, a number of research papers report on surveys of the ISO 9001 and its effects on SMEs (Acharya et Ray 2000; Arend 2006; Quazi et al. et al., 2002; Staines 2000; Heras et al.,2002). The findings of some of them typically show high costs, disappointment and issues relating to consultants and auditors. Although, some report beneficial outcomes of being small.

Prajogo et Brown (2006) report the benefits of being small include: change is quicker to implement owing to fewer management layers, the ability to make decisions quicker, fewer staff members to train and the ease of communication, visible and accessible leadership at the workplace. However, for SMEs, Chittenden, Hall, and Hutchinson (1996) found that ISO 9000 registration resulted in increased overhead costs, increased inspection/supervision, reduced flexibility and increased labour costs as the main reasons why small businesses do not use ISO 9000. It was perceived that certification would increase their costs, add too much paperwork and was a time-consuming process (Yusof et Aspinwall 2000).

In summary, from the literature review, the reported motives can be grouped into two broad categories: internal and external motivations (Table 2). Internal motives are related to the goal of achieving organisational improvement while external motives are mainly related to promotional and marketing issues, customer pressures and market share gains (Brown et al., 1998; Gotzamani et Tsiotras 2002). Like the motives, ISO 9001 certification benefits can also be grouped into external and internal categories (Bhuiyan et Alam 2005; Brown et al., 1998; Buttle 1997; HerasSaizarbitoria et al., 2012; Tarí et al., 2012).

Table 2. ISO 9001 certification's External and Internal motives/benefits.

\begin{tabular}{|ll|}
\hline External motives/benefits & Internal motives/benefits \\
access to new markets & personnel motivation \\
corporate image improvement & product defect rate decreases \\
market share improvement & productivity improvements \\
ISO 9000 certification as a & quality awareness \\
marketing tool & improvements \\
customer relationship & definition of the personnel \\
improvements & responsibilities and obligations \\
customer satisfaction & delivery times improvements \\
customer communication & internal organisation \\
improvements. & improvements \\
& customers complaints \\
& decrease
\end{tabular}


Brazilian Journal of Operations \& Production Management Volume 13, Número 3, 2016, pp. 320-329

DOI: 10.14488/BJOPM.2016.v13.n3.a8 internal communication improvements

product quality improvement

competitive advantage

improvement

All the identified motives and benefits from the literature are incorporated in the questionnaire to understand and analyse the extent to which the reported motives and benefits have effects on Indian SME of manufacturing and service sectors. The hypotheses regarding motives and benefits and its effects on manufacturing and service sectors are developed to test for any significance.

Hypothesis 1: The motives of ISO 9001 certification are same across manufacturing and service SMEs.

Hypothesis 2: The benefits of ISO 9001certification are same across manufacturing and service SMEs

\section{RESEARCH METHODOLOGY}

\subsection{Sampling and data collection}

A survey was carried out in the Indian SMEs representing both manufacturing and service sectors. A random sample of 800 companies was selected from a list of about 1500 ISO 9001 certified manufacturing and service organisations that were recorded in the database of the Ministry of Micro, Small \& Medium Enterprises (MSME) who had applied for certification fee reimbursement scheme initiated by the government of India. The collection method used for the preliminary data was based on a structured questionnaire which was addressed and sent to the quality managers through e-mails. To maintain the true representation of SMEs of different sectors, only one response from one organization was allowed. Finally, after many reminders, 115 completed questionnaires were received thus, representing a response rate of $14.4 \%$.

\subsection{Questionnaire development}

Based on questions describing the demographic profile of the organisation, the measured variables of the ISO 9001 benefits and motivation to pursue it, a questionnaire was developed listing major benefits and motives identified from the literature review. It was further reviewed and pre-tested based on the responses collected from quality managers and academics for its reliability and content validity. The feedback was used to remove ambiguities and modify the contents of the questionnaire. The final questionnaire, thus developed in this way was having ten statements representing possible motives and twelve statements representing possible benefits of ISO 9001 certification. Responses were recorded on a dichotomous-multiple response scales.

\subsection{Data analysis}

Multiple response and cross-tabulation analyses with Chi-square, Phi and Goodman-Kruskal Tau statistics are used to analyse the data and test the hypotheses using SPSS 19.0 (Statistical Package for Social Sciences). Due to the nature of the multiple responses a respondent can choose more than one category to respond to the statements, he seems fit in the situation. The dichotomous data thus collected can represent either the presence or absence of an attribute. Therefore, traditional techniques such as Pearson's product moment correlation or Spearman's rho are not used for analysing correlation.

\section{RESULTS AND DISCUSSION}

\subsection{Organisation Profiles}

Table 3 indicates the characteristics of the respondents who represent the current organization they are working with. The maximum respondents belong to service organisations (55.7\%) while $17.4 \%$ belong to both manufacturing and service organisations. The majority of responses are received from the private organisations (83.5\%) having more than 50 employees which indicate the higher participation of medium size organisations (about $77.4 \%$ ) as compared to small size organization having less than 50 employees. Moreover, middle-level management who represents the managerial and supervisory position and having more than 5 years' work experience constitutes the major part of the respondents $(80.9 \%)$ while a higher level of management (e.g. Owner, President, Director etc.) represents $10.4 \%$ of the total respondents. The majority of the certified organisations have separate quality department/unit (83.5\%) and conduct business in international markets (70.4\%).

Table 3. Demographic Profiles of Respondents

\begin{tabular}{|l|l|l|}
\hline \multicolumn{1}{|c|}{ Type/Size } & No. of Responses & Percentage \\
\hline A. Organisation Type & & \\
a. Manufacturing & 31 & 27.0 \\
b. Service & 64 & 55.7 \\
c. Both & 20 & 17.4 \\
Total & 115 & 100 \\
\hline B.Ownership & & \\
a. Private & 96 & 83.5 \\
b. Government & 9 & 7.8 \\
c. Semi-Government & 10 & 8.7 \\
Total & 115 & 100 \\
\hline C. No. of Employee & & \\
a. Less than 10 & 7 & 6.1 \\
b. 10-25 & 7 & 6.1 \\
c. $26-50$ & 12 & 10.4 \\
d. $51-75$ & 12 & 10.4 \\
e. 76 or more & 77 & 67.0 \\
Total & 115 & 100 \\
\hline
\end{tabular}




\begin{tabular}{|l|l|l|}
\hline D. The level of & & \\
Management & 10 & 8.7 \\
a. Lower & 93 & 80.9 \\
b. Middle & 12 & 10.4 \\
c. Higher & 115 & 100 \\
Total & & \\
\hline E.Business with & & \\
International markets & 34 & 29.6 \\
a.No & 81 & 70.4 \\
b.Yes & 115 & 100 \\
Total & & \\
\hline F.Presence of Separate & \\
Quality department/unit & 19 & 16.5 \\
a.No & 96 & 83.5 \\
b.Yes & 115 & 100 \\
Total & \multicolumn{2}{|l}{} \\
\hline
\end{tabular}

\subsection{Multiple Response Analysis}

\subsubsection{Motives of ISO 9001}

Table 4 presents the responses of the respondents on 10 most likely motives reported in various studies undertaken in different countries. Out of the ten statements regarding likely motives, respondents are asked to choose any number of statements they feel suitable to mark their responses. The most prominent motive that drives SMEs to pursue ISO 9001 certification, reported by $76.5 \%$ of the respondents is that it increases customer satisfaction. Since customer satisfaction, according to ISO is one of the main objectives of ISO 9001 which establishes confidence and trust in customers that their supplier demonstrates the ability to consistently provide products/services that meet customers' requirements. This finding is consistent with the ISO 9001's stated 10 motives for SMEs. Furthermore, $70.4 \%$ respondents have reported the motive that ISO 9001 certification improves the quality of the products/services followed by $65.2 \%$ who are motivated by certification's image that it provides a competitive advantage to the organisation. However, ISO 9001described by the critics as one of the effective marketing and promotional tools is agreed by only $47 \%$ of the respondents which indicate that the majority of the respondent do not see it as mere a tool for marketing and promoting the organisation. In addition, only a minimum $27.8 \%$ respondents have reported that they seek ISO 9001 certification with a motive that it actually reduces the overall cost of the organization. Furthermore, only $5.2 \%$ respondents have decided not to choose any statement to mark their responses.

\subsubsection{Benefits of ISO 9001 certification}

Table 5 presents the benefits that organizations have received from certification to ISO 9001.The majority of the respondents (64.3\%) have reported that customer satisfaction has improved considerably followed by $63.5 \%$ who reported that the quality of the products/services has improved considerably since the organisation has been certified to ISO 9001. Moreover, growth in market share has been reported by $50.4 \%$, growth in profits by $46.1 \%$, and improvement in employees' satisfaction by $45.2 \%$ of the respondents. However, only $29.6 \%$ respondents have claimed that man/machine utilization rate has actually improved to a great extent while only a minimum $26.1 \%$ respondents have reported that overall cost has decreased to a great extent after implementing ISO 9001. However, only $9.6 \%$ respondents have not responded to any statements.

\begin{tabular}{|c|c|c|c|c|}
\hline & Statements & $\mathrm{N}$ & Percent & Percent of Cases \\
\hline 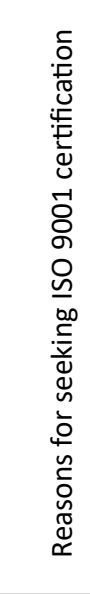 & $\begin{array}{l}\text { 1. Gives competitive advantage to organisation } \\
\text { 2. Improves product/service quality } \\
\text { 3. Increases customer satisfaction } \\
\text { 4. Reduces number of rejections/complaints } \\
\text { 5. Increases productivity/efficiency } \\
\text { 6. Effective marketing/promotional tool } \\
\text { 7. Required by the customers/foreign markets } \\
\text { 8. Makes employees quality aware } \\
\text { 9. Increases organisation's profit } \\
\text { 10. Reduces organisation's overall cost } \\
\text { No response }\end{array}$ & $\begin{array}{l}75 \\
81 \\
88 \\
49 \\
56 \\
54 \\
45 \\
54 \\
44 \\
32 \\
6\end{array}$ & $\begin{array}{l}12.8 \% \\
13.9 \% \\
15.1 \% \\
8.4 \% \\
9.6 \% \\
9.2 \% \\
7.7 \% \\
9.2 \% \\
7.5 \% \\
5.5 \% \\
1.0 \%\end{array}$ & $\begin{array}{c}65.2 \% \\
70.4 \% \\
76.5 \% \\
42.6 \% \\
48.7 \% \\
47.0 \% \\
39.1 \% \\
47.0 \% \\
38.3 \% \\
27.8 \% \\
5.2 \%\end{array}$ \\
\hline Total & & 584 & $100.0 \%$ & $507.8 \%$ \\
\hline
\end{tabular}


Table 5. Benefits of ISO 9001 certification

\begin{tabular}{|c|c|c|c|c|}
\hline & \multirow{2}{*}{ Statements } & \multicolumn{2}{|c|}{ Responses } & \multirow{2}{*}{$\begin{array}{c}\text { Percent of } \\
\text { Cases }\end{array}$} \\
\hline & & $\mathbf{N}$ & Percent & \\
\hline \multirow{13}{*}{ 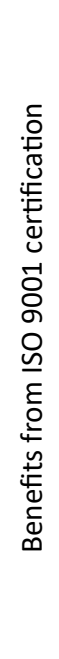 } & 1. The quality of our products/services has improved considerably & 73 & $12.0 \%$ & $63.5 \%$ \\
\hline & 2. The delivery of our products/ services has improved to a great extent & 47 & $7.7 \%$ & $40.9 \%$ \\
\hline & 3. Customer satisfaction has improved considerably & 74 & $12.2 \%$ & $64.3 \%$ \\
\hline & 4. Products/services failure rate has decreased to a great extent & 44 & $7.2 \%$ & $38.3 \%$ \\
\hline & 5. Product/service reliability performance has improved considerably & 54 & $8.9 \%$ & $47.0 \%$ \\
\hline & 6. Man/machine utilization rate has improved to a great extent & 34 & $5.6 \%$ & $29.6 \%$ \\
\hline & 7. Wastage has reduced to a great extent & 41 & $6.7 \%$ & $35.7 \%$ \\
\hline & 8. Market share has grown considerably & 58 & $9.5 \%$ & $50.4 \%$ \\
\hline & 9. Profits have grown over to a great extent & 53 & $8.7 \%$ & $46.1 \%$ \\
\hline & 10. Operating income has grown to a great extent & 38 & $6.2 \%$ & $33.0 \%$ \\
\hline & 11. Overall cost of manufacturing/service has decreased to a great extent & 30 & $4.9 \%$ & $26.1 \%$ \\
\hline & 12. Employee satisfaction has improved considerably & 52 & $8.5 \%$ & $45.2 \%$ \\
\hline & No response & 11 & $1.8 \%$ & $9.6 \%$ \\
\hline \multicolumn{2}{|c|}{ Total } & 609 & $100.0 \%$ & $529.6 \%$ \\
\hline
\end{tabular}

Note: Percent of cases exceed total $100 \%$ due to multi-responses chosen by the respondents

\subsection{Cross-tabulation analysis to test Hypotheses}

The cross-tabulation table is the basic technique for examining the relationship between two categorical variables, possibly controlling for additional layering or controlling variables. From the cross-tabulation alone, it is impossible to tell whether the observed differences in the relationship are real or due to chance variation. To check and test the differences, the crosstabs procedure offers tests of independence and measures of association and agreement for categorical data. The chi-square test measures the discrepancy between the observed cell counts and expected if the rows and columns are unrelated. While the chi-square test is useful for determining whether there is a relationship, it does not tell the strength of the relationship. Thus, Symmetric measures attempt to quantify this. The Symmetric measures are based on the chi-square statistic and Phi statistic (ratio of the chi-square statistic to the weighted total number of observations). It is the most "optimistic" of the symmetric measures, and unlike most association measures, does not have a theoretical upper bound when either of the variables has more than two categories. However, Phi statistic gives some sense of the strength of the association, it does not, in general, have an intuitive interpretation. To develop a clearer sense of this, the directional measure such as Goodman and Kruskal Tau quantifies the reduction in the error of predicting the row variable value when the column variable value is known or vice versa. Tau defines error as the misclassification of a case, and cases are classified into category j with probability equal to the observed frequency of category j.

\subsubsection{Hypothesis 1: The motives of ISO 9001certification are same across manufacturing and service SMEs.}

Table 7 presents the results of the test of significance of motives of ISO 9001 across manufacturing and service SMEs. The two-sided asymptotic significance of the chisquare statistic across all the listed motives except one, that is, it increases the profits of the organisation is greater than 0.05 , so it is safe to say that the motives of getting certified to ISO 9001 are same across manufacturing and service SMEs. In addition, ISO 9001 certification increases the profits of the organization, widely regarded as one of the main motives, is not supported by the result of this study. The p-value for this result is .015 which is less than .05 indicating a significant difference between manufacturing and service SMEs regarding this particular motive. Based on this result, it is safe to say that the motive of increased profits ISO 9001certification provides to manufacturing and service SMEs is not supported by the results of this study.

Moreover, the Phi value of all the listed motives is under 0.3 which indicates that the relationship between motives and SMEs of manufacturing and services sector is not very strong. For instance, the relationship strength is about $14 \%$ between manufacturing and service SMEs and one of the motives that says ISO 9001 gives a competitive advantage to the organisation which respondents choose to say either yes or no. Furthermore, the Goodman and Kruskal Tau also reports very small values of reduction of misclassification error. For example, respondents who says yes to the statement that ISO 9001 gives a competitive advantage to the 
Brazilian Journal of Operations \& Production Management

Volume 13, Número 3, 2016, pp. 320-329

DOI: 10.14488/BJOPM.2016.v13.n3.a8

Table 6. Statistical Tests for testing motives of ISO 9001 certification across Industry

\begin{tabular}{|c|c|c|c|c|c|c|c|}
\hline \multirow[t]{2}{*}{ Reasons for seeking ISO 9001 certification } & \multicolumn{3}{|c|}{ Chi-Square test } & \multicolumn{2}{|c|}{$\begin{array}{l}\text { Symmetric } \\
\text { Measure Phi }\end{array}$} & \multicolumn{2}{|c|}{$\begin{array}{l}\text { Directional measure } \\
\text { Goodman and } \\
\text { Kruskal Tau (Industry } \\
\text { dependent) }\end{array}$} \\
\hline & Value & df & $\begin{array}{l}\text { Asym. Sig. } \\
\text { (2-Sided) }\end{array}$ & Value & $\begin{array}{l}\text { Approx. } \\
\text { Sig. }\end{array}$ & Value & Approx. Sig. \\
\hline 1. Gives competitive advantage to organisation & 2.259 & 2 & .323 & .140 & .323 & .012 & .257 \\
\hline 2. Improves product/service quality & .007 & 2 & .997 & .008 & .997 & .000 & .997 \\
\hline 3. Increases customer satisfaction & 2.805 & 2 & .246 & .156 & .246 & .012 & .267 \\
\hline 4. Reduces number of rejections/complaints & 1.176 & 2 & .556 & .101 & .556 & .007 & .469 \\
\hline 5. Increases productivity/efficiency & .154 & 2 & .926 & .037 & .926 & .001 & .929 \\
\hline 6. Effective marketing/promotional tool & 2.640 & 2 & .267 & .152 & .267 & .015 & .185 \\
\hline 7. Required by the customers/foreign markets & 4.427 & 2 & .109 & .196 & .109 & .022 & .081 \\
\hline 8. Makes employees quality aware & .667 & 2 & .717 & .076 & .717 & .003 & .701 \\
\hline 9. Increases organisation's profit & 8.379 & 2 & $.015^{*}$ & .270 & $.015^{*}$ & .031 & $.029 *$ \\
\hline 10. Reduces organisation's overall cost & 2.693 & 2 & .260 & .153 & .260 & .011 & .287 \\
\hline
\end{tabular}

Table 7. Statistical Tests for testing benefits from ISO 9001 certification

\begin{tabular}{|c|c|c|c|c|c|c|c|}
\hline \multirow[t]{2}{*}{ Benefits from ISO 9001 certification } & \multicolumn{3}{|c|}{ Chi-Square test } & \multicolumn{2}{|c|}{$\begin{array}{l}\text { Symmetric } \\
\text { Measure Phi }\end{array}$} & \multicolumn{2}{|c|}{$\begin{array}{l}\text { Directional measure } \\
\text { Goodman and Kruskal } \\
\text { Tau (Industry depen- } \\
\text { dent) }\end{array}$} \\
\hline & Value & df & $\begin{array}{l}\text { Asym. Sig. } \\
\text { (2-Sided) }\end{array}$ & Value & $\begin{array}{l}\text { Approx. } \\
\text { Sig. }\end{array}$ & Value & $\begin{array}{l}\text { Approx. } \\
\text { Sig. }\end{array}$ \\
\hline $\begin{array}{l}\text { 1. The quality of our products/ } \\
\text { services has improved considerably }\end{array}$ & 1.387 & 2 & .500 & .110 & .500 & .005 & .587 \\
\hline $\begin{array}{l}\text { 2. The delivery of our products/ } \\
\text { services has improved to a great extent }\end{array}$ & 2.192 & 2 & .334 & .138 & .334 & .012 & .243 \\
\hline $\begin{array}{l}\text { 3. Customer satisfaction has improved } \\
\text { considerably }\end{array}$ & .852 & 2 & .653 & .086 & .653 & .004 & .665 \\
\hline $\begin{array}{l}\text { 4. Products/services failure rate has } \\
\text { decreased to a great extent }\end{array}$ & 1.814 & 2 & .404 & .126 & .404 & .010 & .316 \\
\hline $\begin{array}{l}\text { 5. Product/service reliability } \\
\text { performance has improved considerably }\end{array}$ & .608 & 2 & .738 & .073 & .738 & .003 & .675 \\
\hline $\begin{array}{l}\text { 6. Man/machine utilization rate has } \\
\text { improved to a great extent }\end{array}$ & .735 & 2 & .693 & .080 & .693 & .004 & .632 \\
\hline 7. Wastage has reduced to a great extent & .762 & 2 & .683 & .081 & .683 & .004 & .634 \\
\hline 8. Market share has grown considerably & .286 & 2 & .867 & .050 & .867 & .001 & .898 \\
\hline 9. Profits have grown over to a great extent & 5.108 & 2 & .078 & .211 & .078 & .018 & .128 \\
\hline $\begin{array}{l}\text { 10. Operating income has grown to a great } \\
\text { extent }\end{array}$ & 2.647 & 2 & .266 & .152 & .266 & .008 & .384 \\
\hline $\begin{array}{l}\text { 11. Overall cost of manufacturing/ } \\
\text { service has decreased to a great extent }\end{array}$ & 3.681 & 2 & .159 & .179 & .159 & .019 & .110 \\
\hline $\begin{array}{l}\text { 12. Employee satisfaction has improved } \\
\text { considerably }\end{array}$ & 5.6472 & 2 & .059 & .223 & .059 & .032 & $.027^{*}$ \\
\hline
\end{tabular}


organisation, the Goodman and Kruskal's tau value of 0.012 with the industry dependent (Manufacturing or service) means that there is only $1.2 \%$ reduction in misclassification which is considered to be very poor.

\subsubsection{Hypothesis 2: The benefits of ISO 9001certification are same across manufacturing and service SMEs}

Table 7 presents the results of the test of significance of benefits received from certification to ISO 9001 across manufacturing and service SMEs. The two-sided asymptotic significance of the chi-square statistic across all the listed benefits is greater than 0.05 . Therefore, it is safe to say that the benefits received from certification to ISO 9001 are same across manufacturing and service SMEs.

However, the Phi value of all the listed benefits is under 0.3 which indicates that the relationship between benefits received across SMEs of manufacturing and services sector is not very strong. For instance, the relationship strength is about $8.6 \%$ between manufacturing and service SMEs and one of the benefits that says customer satisfaction has improved considerably after certification to ISO 9001. Furthermore, the Goodman and Kruskal Tau also reports very small values of reduction of misclassification error. For example respondents who says yes to the statement that customer satisfaction has improved considerably, the Goodman and Kruskal's tau value of 0.004 with the industry dependent (Manufacturing or service) means that there is only $0.4 \%$ reduction in misclassification error.

\section{CONCLUSION}

In summary, the results from the multiple response analysis and cross-tabulation statistical tests, confirmed that there seems no significant difference in benefits received from certification to ISO 9001 across SMEs of manufacturing and service sectors. However, the strength of the relationship between benefits and SMEs of manufacturing and service sectors has been very poor indicating the varying level of benefits derived by the organisations. This finding is in line with Arauz et Suzuki (2004) who suggest that motivation to pursue certification influence the performance of the standard and vary according to firm size. Small, medium and large firms have varied interests and motives and thus, have different effects of certification on their performance. Furthermore, one of the widely accepted motives of ISO 9001 that says certification leads to increased profits has not been supported by the results of this study. Consequently, the majority of the SMEs of manufacturing and service sectors have reported that the certification's appeal of increased customers satisfaction and improved quality of products/services motivated them to seek ISO 9001 certification. Moreover, the criticism of ISO 9001 as an effective marketing and promotional tool has not found significant support in this study.

\section{LIMITATIONS AND FUTURE IMPLICATIONS FOR RESEARCH}

Since the analysis is based on a single response from each company, there is a possibility of single respondent bias. Future research should consider collecting from multiple individuals from a company to avoid this bias and may include large organisations as well in the sample to analyse and test the differences in benefits and motives between large, and small and medium size organization. Moreover, this study is based on the cross-sectional data, future research may consider longitudinal data to assess the benefits more precisely as newly certified organisations take longer time to realize the real benefits of the certification.

\section{REFERENCES}

Acharya, U.H. \& Ray, S., 2000. ISO 9000 certification in Indian industries: A survey. Total Quality Management, 11(3), pp.261-266.

Alfonso Rodríguez-Escobar, J., Gonzalez-Benito, J. \& Rafael Martínez-Lorente, A., 2006. An analysis of the degree of small companies' dissatisfaction with ISO 9000 certification. Total Quality Management \& Business Excellence, 17(4), pp.507-521.

Arauz, R. \& Suzuki, H., 2004. ISO 9000 Performance in Japanese Industries. Total Quality Management \& Business Excellence, 15(1), pp.3-33.

Arend, R.J., 2006. SME-supplier alliance activity in manufacturing: contingent benefits and perceptions. Strategic Management Journal, 27(8), pp.741-763.

Bhuiyan, N. \& Alam, N., 2005. An investigation into issues related to the latest version of ISO 9000. Total Quality Management \& Business Excellence, 16(2), pp.199-213.

Brown, A., van der Wiele, T. \& Loughton, K., 1998. Smaller enterprises' experiences with ISO 9000. International Journal of Quality \& Reliability Management, 15(3), pp.273-285.

Buttle, F., 1997. ISO 9000: marketing motivations and benefits. International Journal of Quality \& Reliability Management, 14(9), pp.936-947.

Chittenden, F., Hall, G. \& Hutchinson, P., 1996. Small firm growth, access to capital markets and financial structure: Review of issues and an empirical investigation. Small Business Economics, 8(1), pp.59-67.

Conti, T., 2004. How to Conceptually Harmonize ISO 9000 Certification, Levels of Excellence Recognition and Real Improvement. Total Quality Management \& Business Excellence, 15(5-6), pp.665-677.

Gotzamani, K.D. \& Tsiotras, G.D., 2002. The true motives behind ISO 9000 certification. International Journal of Quality \& Reliability Management, 19(2), pp.151-169. 
Heras, I., Dick, G.P.M. \& Casadesús, M., 2002. ISO 9000 registration's impact on sales and profitability. International Journal of Quality \& Reliability Management, 19(6), pp.774791.

Heras-Saizarbitoria, I., Marimon, F. \& Casadesús, M., 2012. An empirical study of the relationships within the categories of the EFQM model. Total Quality Management \& Business Excellence, 23(5-6), pp.523-540.

Prajogo, D.I. \& Brown, A., 2006. Approaches to adopting quality in SMEs and the impact on quality management practices and performance. Total Quality Management \& Business Excellence, 17(5), pp.555-566.

Quazi, H. a., Hong, C.W. \& Meng, C.T., 2002. Impact of ISO 9000 certification on quality management practices: A comparative study. Total Quality Management, 13(1), pp.53-67.

Singels, J. et al., 2001. ISO 9000 series - Certification and performance. International Journal of Quality \& Reliability Management, 18(1), pp.62-75.

Staines, A., 2000. Benefits of an ISO 9001 certification the case of a Swiss regional hospital. International Journal of Health Care Quality Assurance, 13(1), pp.27-33.

Tarí, J.J., Molina-Azorín, J.F. \& Heras, I., 2012. Benefits of the ISO 9001 and ISO 14001 standards: A literature review. Journal of Industrial Engineering and Management, 5(2), pp.297-322.

Yusof, S.M. \& Aspinwall, E., 2000. TQM implementation issues: review and case study. International Journal of Operations \& Production Management, 20(6), pp.634-655. 